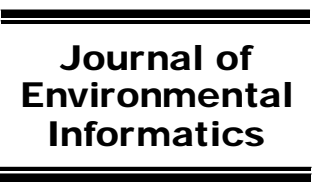

www.iseis.org/jei

\title{
A Process for Harmful Algal Bloom Location Prediction Using GIS and Trend Analysis for the Terrestrial Waters of Kuwait
}

\author{
B. N. Shuhaibar ${ }^{*}$ and R. Riffat \\ Civil and Environmental Engineering Dept., George Washington University, Washington, DC, NW 20052, USA
}

Received 13 February 2008; revised 27 August 2008; accepted 10 September 2008; published online 1 December 2008

\begin{abstract}
The State of Kuwait has a population of 2.5 million people, the vast majority of whom live along the southeastern stretch of its $500 \mathrm{~km}$ coastline. This makes the health of its coastal waters vital to the overall quality of life and economy of the country. Kuwait Bay, a shallow natural harbor situated at the eastern "mouth" of the country, lies year-round within the euphotic zone. It is exposed to many environmental stressors that originate from both point and non-point-sources. A combination of factors has led to a marked increase in harmful algal bloom (HAB) outbreaks over the past two decades. Even though they are ephemeral, these HABs have been massive and costly in environmental and economic terms. The objective of this study was to attempt to develop a process to identify potential $\mathrm{HAB}$ "hotspots" using GIS and trend analysis techniques, in an effort to isolate the areas that are most prone to a future HAB outbreak. ArcGIS and Crystal Ball software were used to process and analyze data provided by the Kuwait Environmental Public Authority. Data was projected over a one-year period and subsequently used to generate monthly rasters (digital images) that outlined any HAB "hotspots" present for the given month. The results showed that, although a broad snapshot of HAB-friendly conditions was produced for each month between May and October, no specificity could be applied in the context of a definite algal outbreak. Further research is needed for a more accurate process to be developed.
\end{abstract}

Keywords: dissolved oxygen, eutrophication, GIS, HAB, Map Algebra, trend analysis

\section{Introduction}

Harmful algal bloom (HAB) sightings have been documented across the globe, from the Eastern United States seaboard to the coasts of the Australasian continent. It has become the consensus of scientists that the frequency of HABs is increasing worldwide, which has triggered an amplified interest in their study and understanding.

This higher rate of incidence has been attributed to a number of factors, ranging from the increase in coastal eutrophication to the constant transport of new species by cargo ship ballast water. Of all these factors, the aforementioned increase in eutrophication is the most critical. As the world human population continues to grow at an exponential rate, so too does its demands for the resources and raw materials necessary for continued existence. This higher demand translates to more crops being farmed, more energy being consumed and more waste being generated. The subsequent nutrient loading on the water bodies of the world can only mean that their over-productivity rates will increase, thus providing optimal conditions for HABs to thrive in the more temperate regions.

\footnotetext{
${ }^{*}$ Corresponding author. Tel.: +1 202 3866215; fax: +1 6306047146. E-mail address: bshuhaibar@aol.com (B. N. Shuhaibar).
}

ISSN: 1726-2135 print/1684-8799 online

(C) 2008 ISEIS All rights reserved. doi:10.3808/jei.200800134
Even though there are a wide variety of species that have different effects on humans and ecosystems, the nature of the problems are often similar, as are their mitigation techniques. As awareness of the threats related to HABs has spread throughout the world, many nations are working together to deal with the threats to coastal economies and ecosystems. The Intergovernmental Oceanographic Commission (IOC) of UNESCO, the International Council for Exploration of the Seas (ICES), the Scientific Committee for Oceanic Research (SCOR), the European Union (EU) and the Asia Pacific Economic Cooperation Program (APEC) are some of these cooperating international groups.

The northwestern Persian Gulf state of Kuwait is not immune to the presence of HABs. Several large-scale blooms have been observed and documented over the past 2 decades or so, with some being responsible for massive fish kills and widespread beach closures. The natural and environmentally-stressed harbor of Kuwait Bay has been the most prone to both the onset and negative effects of HABs, and is the main area of focus in this study.

A GIS (Geographic Information System) is used to store, manipulate, process and analyze spatial data. They are developed for a wide range of applications in a diverse spectrum of industries. As HABs occur in a spatial setting (marine waters and so on), outbreaks can be visually represented in a GIS. In addition, related parametric data can be added which can later be processed and analyzed using GIS software and its relevant 
extensions.

The main objective of this research was to combine several modular activities (data projection, GIS data processing techniques, output analysis) into the development of a process to identify potential hotspots of HAB formation and, in turn, provide the possibility of predicting the next major HAB outbreak. A secondary objective is to ensure the entire process is technologically efficient and user-friendly enough to be used in any region of the world afflicted by HAB outbreaks.

\section{Background}

\subsection{Harmful Algal Blooms}

Harmful algae are microscopic, single celled-plants (phytoplankton) that live in marine environments. Some phytoplankton species contain reddish pigments, which is primarily responsible for the red discoloration observed during their periodic blooms. In addition, they can be toxic and it is for this reason that they have been collectively referred to as "harmful algal blooms (HAB).” Toxic phytoplankton can be categorized into three main groups: dinoflagellates, prymnesiophytes and chloromonads. Of these, dinoflagellates are the most common and of greatest interest within the scope of this research.

A bloom develops when the phytoplanktons photosynthesize and multiply, converting dissolved nutrients and sunlight into plant biomass. The mode of reproduction is simple asexual fission, much like the procreative behavior of bacteria. Given the right amounts of nutrients and light, and deficiency in the heavy grazing by tiny zooplankton that consume the algae, the population size can increase very rapidly. In severe cases, a milliliter of sea water can contain tens or hundreds of thousands of algal cells (Anderson, 1994).

Of all species of phytoplankton, only a relatively small percentage is toxic; indeed, marine life would cease to exist in the absence of the single-celled organisms. However, the small number of species that are harmful produce potent neurotoxins that bioaccumulate and/or biomagnify through the food web where they affect and may even kill the consumers within higher trophic levels. Human exposure to and subsequent health affects resulting from harmful algae stems from the consumption of contaminated fish and shellfish.

Although exact trigger factors have not yet been ascertained, the literature points to several parameters that contributes to both the presence of an algal bloom as well as its longevity. As phytoplanktons are microscopic marine flora, they have the same basic requirements as other plants in order to photosynthesize and reproduce. Light, dissolved oxygen and a nutrientrich food source are all necessary factors in phytoplankton life cycles. A HAB initiation is a result of the availability of the aforementioned factors coupled with favorable or optimal conditions ambient water temperature, water column stability, $\mathrm{pH}$ levels and other factors.

The $\mathrm{N}$ : P (Nitrogen : Phosphorus) ratio has repeatedly been cited as one of the most important facors contributing to the promulgation and longevity of a HAB. The Redfield Ratio (Redfield, 1934) defines the $\mathrm{N}$ : $\mathrm{P}$ ratio necessary to sustain aquatic life as $16: 1$. However, empirical studies have shown that this value can be substantially lower when other parameters are present and in optimal quantities and/or levels.

As phytoplanktons are mesophilic, their populations thrive in temperatures ranging from $20 \sim 45^{\circ} \mathrm{C}$. A minimum dissolved oxygen (DO) level of $4.8 \mathrm{mg} / \mathrm{L}$ is another necessary condition, defined as the chronic criterion for growth (CCG) in saltwater environments (US EPA Aquatic Life Criteria, 2008).

\subsection{HAB in Kuwait Waters}

The Persian Gulf (Figure 1) is a shallow, semi-enclosed marginal sea with a single outlet through the Straits of Hormuz at its southeastern point. These factors contribute to its lengthy flushing time of 3 to 5 years. Its high salinity of up to $44.3 \%$ can be attributed to this factor in addition to the high rate of evaporation relative to coastal freshwater inputs. This fact coupled with the semi-enclosed nature of the Gulf causes it to act as a negative estuary, as well as pollutant traps (Subba Rao et al., 2003). Persian Gulf water temperatures vary from $12^{\circ} \mathrm{C}$ to greater than $32^{\circ} \mathrm{C}$, and they are subject to anthropogenic as well as natural environmental stresses. One of the largest sources of anthropogenic pollution of the Gulf is a spill of approximately 200,000 barrels of oil annually.

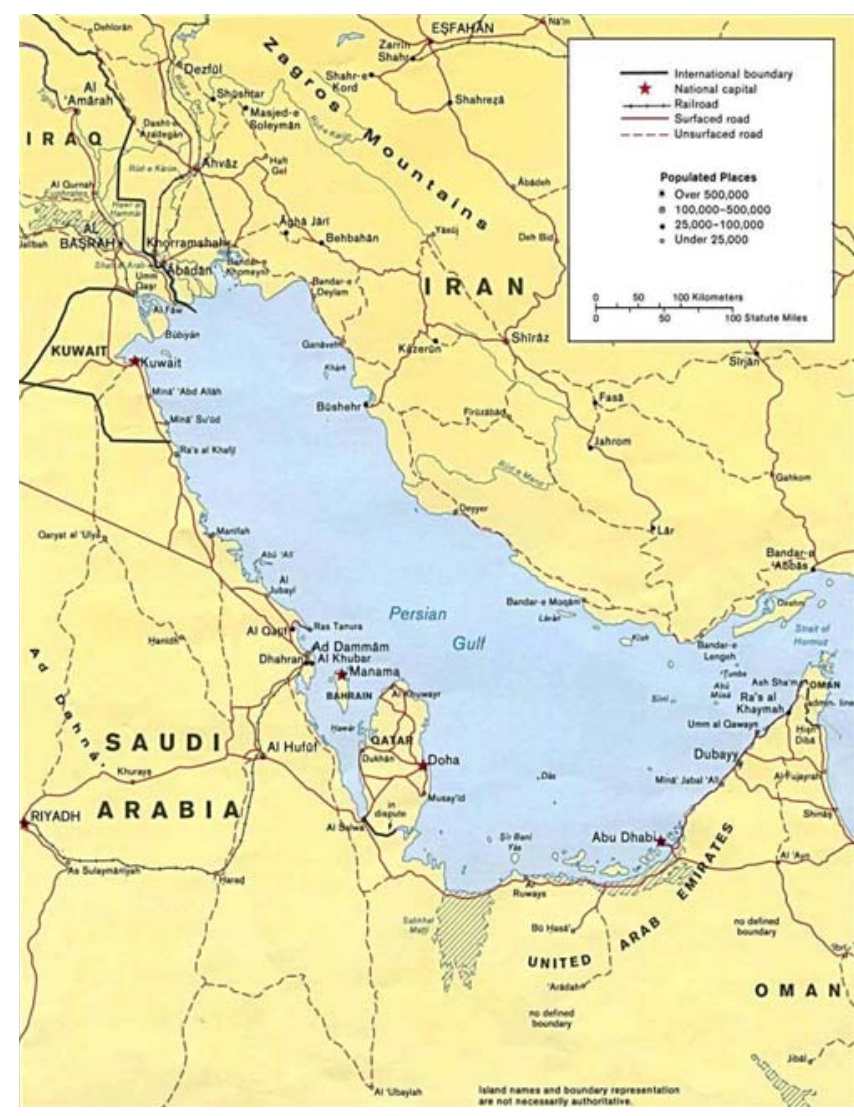

Figure 1. The Persian Gulf (Reisenett, 2008).

Nutrients are mainly carried into the Gulf via a drainage 
channel built after the Gulf War of 1991 by Iraq that drains its southwest Al-Ahwar wetlands directly into the Gulf's northern region. In addition, the various industrial and sewage treatment effluents from the northern Gulf countries contribute to the overall water pollution in this sector.

The State of Kuwait (Figure 2) is a constitutional monarchy that is situated at the northwestern end of the Persian Gulf, wedged between Iraq to its north and Saudi Arabia to its south. Its relatively small land area of $17,820 \mathrm{~km}^{2}$ makes it roughly comparable to the size of New Jersey. The 2006 population estimate is roughly 2.42 million people, the vast majority of which live somewhere along the southeastern stretch of its 499 km coastline (Central Intelligence Agency, 2008). Kuwait's main source of revenue is the refining and exporting of crude oil and its fractions.

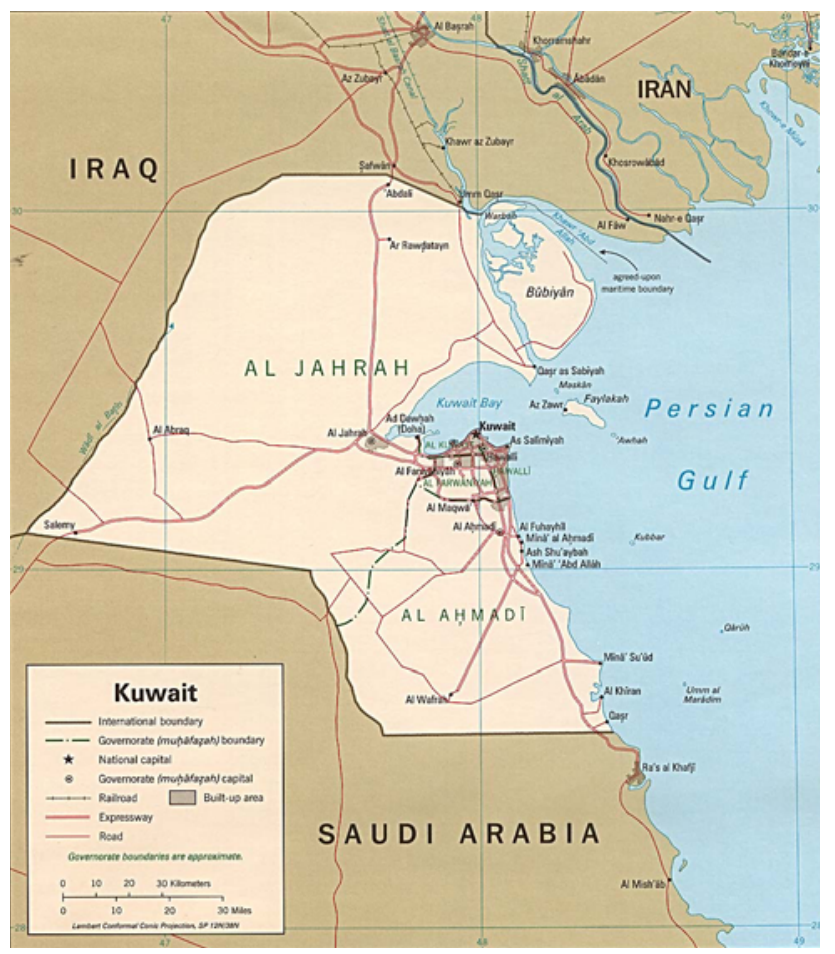

Figure 2. The State of Kuwait (Reisenett, 2008).

Kuwait Bay, located at the "mouth" of the country, is a natural harbor with a maximum depth of $20 \mathrm{~m}$ and mean depth of $>3 \mathrm{~m}$ (Glibert et al., 2002) making it lie within the euphotic zone (the layer of a water body that receives sufficient sunlight to support effective photosynthesis) year-round. The Bay waters receive $325 \sim 375 \mathrm{~W} \cdot \mathrm{m}^{-2}$ (Watts per square metre) and $83 \sim 275 \mathrm{~W} \cdot \mathrm{m}^{-2}$ near the surface and benthic region respectively, which are conditions that are suitable for phytoplankton promulgation (Subba Rao et al., 2003). This has allowed for the recording of an abundance and diversity of phytoplankton in the area. The waters of Kuwait Bay are eutrophic, and always have an abundance of macronutrients (nitrogen, phosphorus and silicate) present. Kuwait Bay is a highly stressed body of water. Sources of this stress include those that are both natural and anthropogenic.

The Shatt al-Arab outflow of $1456 \mathrm{~m}^{3} \cdot \mathrm{s}^{-1}$ is the main natural source of stress in the Bay, in the form of macronutrients loading. Micronutrients are carried by winds in the form of dust storms, of which Kuwait experiences an average of 27 per year (Subba Rao et al., 2003). These nutrients include iron, zinc and copper.

Anthropogenic sources of stress include: discharges from petrochemical companies and refineries; raw and partially treated sewage; sanitary wastewater; desalination plant effluent; slaughter house waste; shipping industry dredging; and aquaculture biomass. Most of these industries are located along the southern coast of Kuwait Bay, and it is their close proximity coupled with the presence of a densely populated living area that contributes to the overall environmental stress of the Bay.

Many HABs have been sighted in Kuwait waters, but not all have been reported; the more massive outbreaks have been studied and documented. One of the earliest anecdotal sightings was by J. M. Al-Hassan in 1981 and 1982, but the first scientific study of a HAB was carried out in $1987 \sim 1988$ (Subba Rao et al., 2003). The most detailed research studies carried out specifically in Kuwait Bay were in: September October 1999 (Heil et al., 2001); July 2000 (Subba Rao et al., 2003); and August September 2001 (Glibert et al., 2002). Each sighting was observed over a period of several days, and in some cases this period overlapped into the following month. Although each and every HAB ended up in Kuwait Bay, sightings always originated along the eastern and southern coastal waters.

\subsection{HAB Forecast and Prediction}

HABs can have serious implications on both marine ecosystems and the quality of human life. In addition, massive fish kills and major water discolorations lead to economic and aesthetic drawbacks. It is therefore in the long-term interest of Kuwait to have some type of HAB predictive method in place to be able to forecast the probability of a red tide outbreak based on favorable ambient conditions.

Although several attempts have been made to provide an “early warning” of a HAB [e.g. telemetry (Lam, 2002)], there are only a few methods that have been employed in order to predict a HAB event. The literature found covers the following concepts:

- Case-based Reasoning (CBR) (Fdez-Riverola, 2003)

- Decision trees and nonlinear piecewise regression (Chen, 2004)

- Genetic programming (GP) (Muttil, 2005)

- Remote sensing (RS) and marine optical sensor combinations (Sacau-Cuadrado et al., 2003; Wynne et al., 2005)

Although fairly successful in their attempts to forecast $\mathrm{HAB}$ onset, all the aforementioned concepts were found to possess two common and substantial drawbacks: firstly, they could be too complex to be understood by anyone other than a specialist in their respective fields; and secondly, the equip- 
ment needed to employ them would be too costly and not very user-friendly in a universal setting. To date, nothing in the literature has been found that describes a Geographic Information System (GIS) as the basis for the generation of a HAB predictive process.

\section{Materials and Methods}

Three computer-based applications comprised the framework of this study. These were:

- $\operatorname{ArcGIS\circledR ~(ESRI)~}$

- Crystal Ball ${ }^{\circledR}$ (Decisioneering)

- Microsoft EXCEL $®$ (Microsoft)

\subsection{Raw Data}

Kuwait Environmental Public Authority (KEPA) is one of several government institutions that monitor the overall environmental health of Kuwait and its national waters. Part of its marine monitoring program consists of a network of buoys set up at relevant locations within Kuwait Bay and all along the southern coast. There are 13 stations in total, and each provides in-situ measurement of a wide spectrum of nutrient, trace metal, hydrocarbon, oceanographic and meteorological parameters. KEPA has provided monthly data ranging from January 1983 to December 2005. There is a data gap between July 1990 and October 1991, representing the duration of the invasion and subsequent Gulf War of that time period.

All data obtained from KEPA was in Microsoft EXCEL ${ }^{\circledR}$ (.xls) format and separated into workbooks representing each monitoring station. These data were then further merged into one workbook, and re-sorted by month and year. This allowed for data to be presented en masse or separately, depending on the processing techniques to be employed. In addition, another workbook was created which contained columns representing parameters relevant only to the scope of this study. This allowed for a much faster and more convenient manner in which to search and process the data.

\subsection{Basic Calculations and Transformations}

The following calculations were carried out in order to compile a table of relevant data that would be usable by ArcGIS:

1) Molar Weights of Nitrogen, Phosphorus and Silicon: The different compounds were expressed as molar weights using the following basic equation:

$M o l=C C \times\left(\frac{A W}{C W}\right)$

where $\mathrm{Mol}=$ molar weight of $\mathrm{N}, \mathrm{P}, \mathrm{Si}$ as derived from respecttive compound; $\mathrm{CC}=$ compound concentration, $\mathrm{mg} / \mathrm{L}$; $\mathrm{AW}=$ atomic weight of $\mathrm{N}, \mathrm{P}$ or $\mathrm{Si}(14,31,28$ respectively); $\mathrm{CW}=$ atomic weight of respective compound $\left(\mathrm{NH}_{3}=17\right.$ etc.).
Total molar $\mathrm{N}$ was calculated by summing up the individual molar $\mathrm{N}$ values.

2) Nutrient Ratios: Once the molar weights were calculated, the different ratios were obtained by dividing one molar value by its relative counterpart. The 3 ratios calculated were $\mathrm{N}: \mathrm{P}, \mathrm{Si}: \mathrm{N}$ and $\mathrm{Si}: \mathrm{P}$.

\subsection{Data Processing - Crystal Ball Predictor}

The data provided by KEPA contained gaps where equipment had malfunctioned, technical issues were faced, or external factors such as the Persian Gulf War of 1991 had denied its access. An algorithm, named ForecastingInterp, was written in Visual Basic for Applications (VBA) to project this missing data. In other words, this algorithm was used to fill in the empty cells found within the columns of the existing data. The flowchart representing this algorithm is shown in Figure 3.

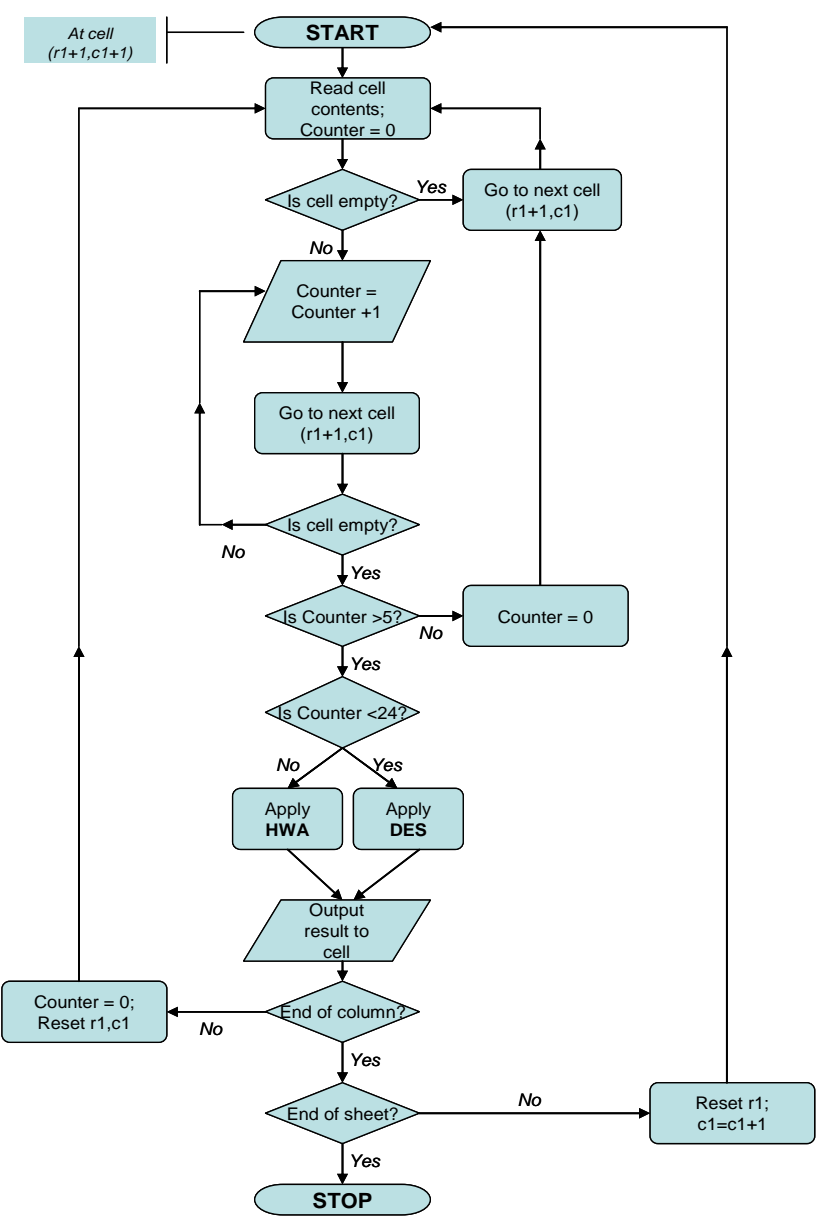

Figure 3. Flowchart of Crystal Ball projection algorithm (Interpolation).

The initial cell in a worksheet, at point (r1, c1), was defined within the code. CB Predictor works along the column of each parameter being projected, i.e. the next cell to be ana- 
lyzed will always be $(\mathrm{r} 1+1, \mathrm{c} 1)$ until the end of that column has been reached. It stores viable data in an array before applying the appropriate analysis technique once a defined point has been reached.

The variables needed to execute the CB-based algorithm were as follows:

- number_of_series: the number of columns that are to be processed. As the data consistency was staggered, this was set to 1 by default.

- number_of_points: the number of cells that contain viable values. This variable is represented by "Counter" in the flowchart in Figure 3.

- seasonality_value: the number of months representing a full seasonal cycle. In this case, this value was set to 12 .

- number_to_forecast: the number of cells to be projected. As the number of consecutive empty cells varied from parameter to parameter, the value for this variable was always 1 . The algorithm would then repeat itself from the beginning of the column until it reached the next empty cell.

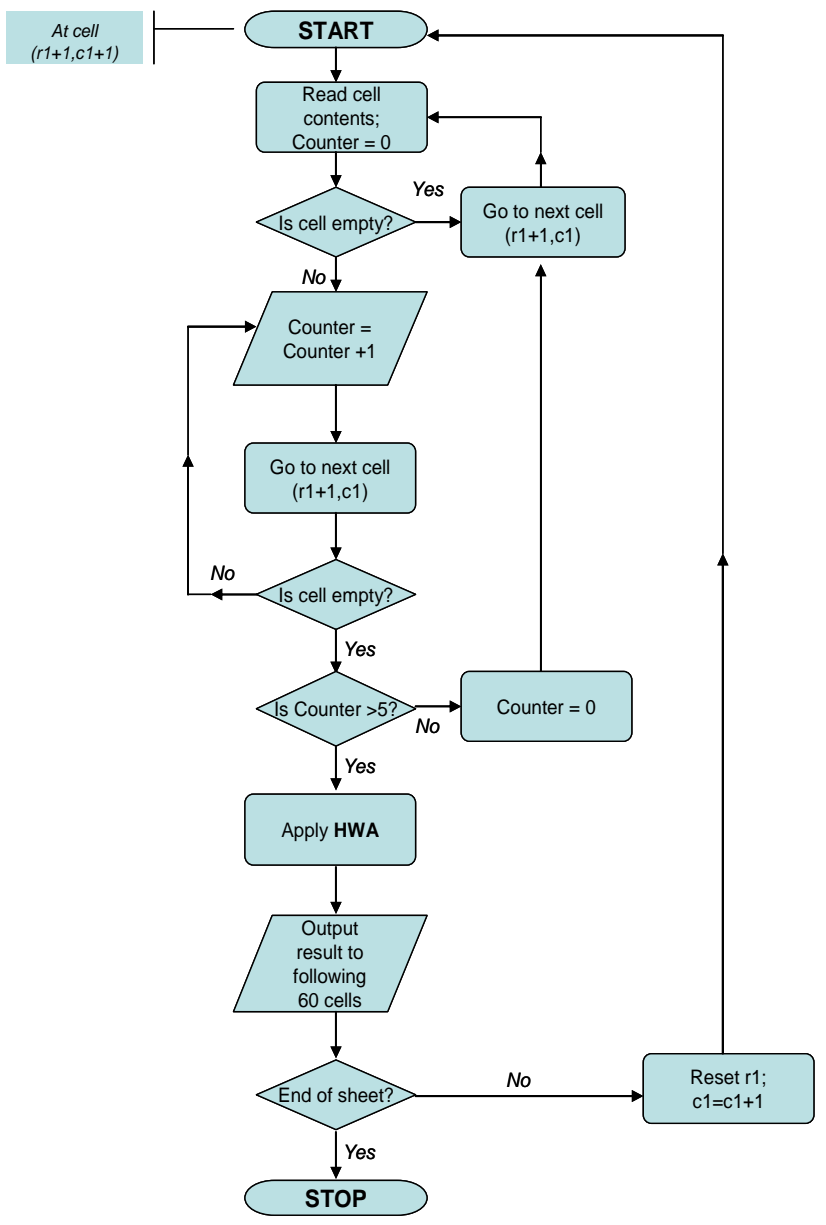

Figure 4. Flowchart of Crystal Ball projection algorithm (Extrapolation).

The projection methods used were:
1) Double exponential smoothing (DES): used if number of points was less than 24 (i.e. two seasonal cycles); or

2) Holts-Winters additive (HWA): used if number of points was 24 or more (i.e. two or more seasonal cycles).

Each projected cell data was then bolded and the entire cell highlighted in yellow in order to distinguish it from the original data. Once all relevant empty cells had been filled in this way, the program carried on to the next column, and so on until all parameters in the worksheet had been processed. This process was repeated (using a "For... Next" loop) for as many worksheets as the workbook contained, which in this case was 13.

After the initial algorithm had been executed to completion, CB Predictor was used to project 12 months' worth of values for each parameter per monitoring station. The algorithm representing this process is shown in Figure 4. As the optimal HAB season falls between the months of May and October, only that range of data was used in further analysis.

In summary, the interpolation algorithm (Figure 3) was used for any data prior to and including 2005, whereas the extrapolation one (Figure 4) was used to provide the data after that date.

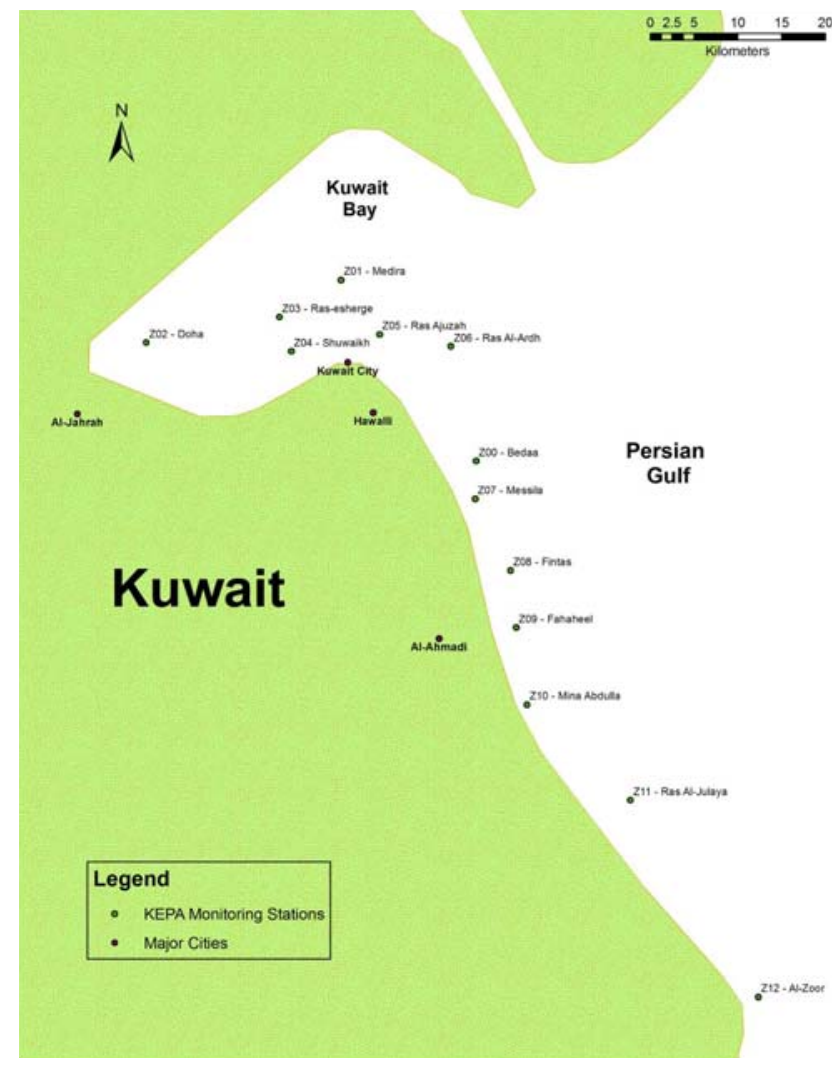

Figure 5. ArcView-generated base map of Kuwait, its major cities and all KEPA marine monitoring stations.

\subsection{Data Processing - ArcGIS}

In order for the .xls files to be recognized by ArcGIS, 
they had to be converted into .dbf format. This was done by executing an algorithm to import the relevant worksheets into Microsoft Access and saving them as database files within the Personal Geodatabase.

A base map of Kuwait was created using data downloaded from the ESRI ArcData data downloader website, which contains country boundaries, water bodies, major cities and other relevant spatial data. The Geographic Coordinate System (GCS) was used for spatial projection, with the World Geodetic Survey 1984 (WGS 1984) as datum. The .dbf files were imported to ArcView and converted to layer (.lyr) files based on the $\mathrm{X}$ and $\mathrm{Y}$ coordinates of each station. The base map and all labeled monitoring stations are shown in Figure 5.

Data representing the 3 parameters of $\mathrm{N}$ : P ratio, water surface temperature, and dissolved oxygen for each date range were then processed using Spatial Analyst. This involved the interpolation of each set of data between the 13 monitoring stations using the inverse distance weighting (IDW) method, represented by Shepard's equation (Shepard, 1968):

$w(d)=\frac{1}{d^{p}}$

where $w(d)=$ weighting factor applied to a known value; $d=$ distance from the known value to the unknown value; $p=$ positive real number (most commonly, $p=2$ ).

Once completed, a color-scheme was applied to the resulting graphic, with the maximum and minimum values of each parameter used as the data range, represented by red-to-blue spectrum of colors, respectively. It should be noted that, due to reasons beyond the control of the authors, all August 2001 tables were missing data for stations Z10 through Z12.

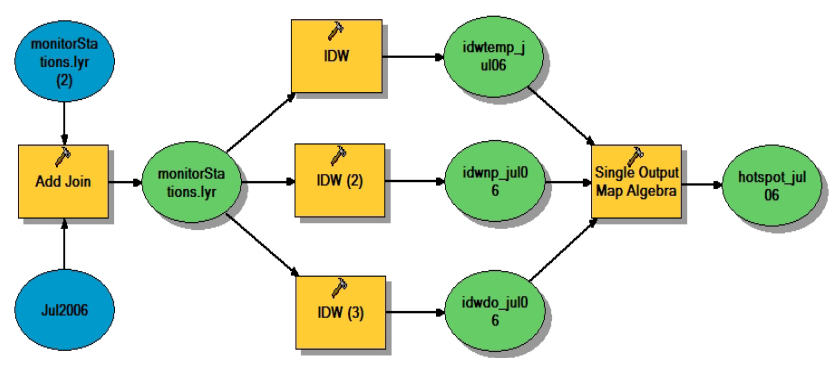

Figure 6. Flowchart outlining hotspot-raster generation and quantitative analysis process in ArcGIS.

\section{5. “Hotspot” Raster Generation and Interpretation}

A final step of compounding all visual interpolated data within a given date range was taken, which could then be qualitatively studied for any potential HAB hotspots. This was also carried out quantitatively by employing "map algebra” techniques: a set of parameters and their relevant ranges for potential HAB promulgation were programmed into the system, which produced a binary color-coded raster displaying potential hotspots upon execution: “1” (green) represented the ar- ea(s) that met the map algebra criteria, and " 0 ” (blue) the area(s) that did not.

The flowchart for this process is shown in Figure 6, with the July 2006 (jul06) projected data as an example. The monitor Stations layer contains all the spatial data needed to spatially represent the Jul2006 parameter data. Therefore, it was necessary to perform a Join function in order to relate the two.

Once joined, an IDW (inverse distance weighting) function was executed over the 3 different parameters of temperature (idwtemp), $\mathrm{N}$ : P ratio (idwnp) and DO (idwdo). Once the output rasters had been generated, map algebra was collectively applied to them based on each respective parameter critical value as criteria, which finally resulted in the hotspot representative map (hotspot_jul2006). This algorithm was looped over every map present in the geodatabase. Once generated, the binary rasters were then compared with those produced for the original $\mathrm{HAB}$ date ranges in order to ascertain whether projected hotspot viability exists and in what capacity.

\subsection{Data Verification and Validation}

The raw data obtained from KEPA had already been used in several reports and published papers (e.g. Glibert et al., 2002) therefore allowing the inference of its validity. The projected data was validated by comparing certain measured parameters against those obtained from field trips carried out in the late summer and early autumn of 2006.

Two separate sampling field trips were carried out in the course of this study's research: one on August $5^{\text {th }}$ of 2006 and the other on October $3^{\text {rd }}$ of 2006. A KISR research boat was taken out to several pre-determined locations that tallied with the existing monitoring stations. A Quanta ${ }^{\circledR}$, a digital in situ measuring device made by Hydrolabs capable of measuring 6 parameters simultaneously, was then used to take readings of water temperature, DO, salinity and $\mathrm{pH}$ levels at each location [the other 2 parameters, ORP (oxidation-reduction potential) and turbidity, were not required for the purposes of this study). Measurements were taken at both surface level and 3m depth, and the subsequent mean calculated. This method was executed during both trips.

The Pearson coefficient was used to determine the correlation between measured and predicted values. The Pearson coefficient (r) was calculated using the following equation:

$r=\frac{S_{x y}}{\sqrt{S_{x x} S_{y y}}}$

where $S_{x x}=\sum_{i=1}^{n}\left(X_{i}-\bar{X}\right)^{2}, S_{y y}=\sum_{i=1}^{n}\left(Y_{i}-\bar{Y}\right)^{2}, S_{x y}=\sum_{i=1}^{n}\left(X_{i}-\bar{X}\right)$. $\left(Y_{i}-\bar{Y}\right), n=$ sample size, $\bar{X}, \bar{Y}=$ mean values of the $X$ and $Y$ variables.

\section{Results and Discussion}

Tables $1 \mathrm{a}$ and $1 \mathrm{~b}$ show the data collected on the field trips for each station specified ("Measured” column) as compared 
Table 1(a). August 2006 Crystal Ball (Projected) vs. Field Trip (Measured) Data for Relevant Parameters

\begin{tabular}{ccccccccc}
\hline Station & \multicolumn{2}{c}{ Water Temp. $\left({ }^{\circ} \mathrm{C}\right)$} & \multicolumn{2}{c}{$\mathrm{pH}$} & \multicolumn{2}{c}{ Salinity (\%) } & \multicolumn{2}{c}{ D.O. (mg/l) } \\
\cline { 2 - 8 } & Projected & Measured & Projected & Measured & Projected & Measured & Projected & Measured \\
\hline Z00 & 31.55 & 28.76 & 7.59 & 8.59 & 40.07 & 48.06 & 6.18 & 4.77 \\
Z01 & 31.49 & 29.16 & 8.16 & 8.56 & 40.63 & 48.50 & 5.92 & 5.16 \\
Z05 & 32.18 & 28.95 & 6.34 & 8.70 & 40.49 & 47.68 & 6.13 & 4.99 \\
Z06 & 30.66 & 29.00 & 7.63 & 8.61 & 40.65 & 48.16 & 6.12 & 4.72 \\
Z07 & 31.87 & 28.94 & 7.74 & 8.57 & 40.17 & 46.88 & 6.41 & 4.95 \\
Z08 & 31.95 & 29.70 & 7.66 & 8.60 & 40.09 & 48.77 & 6.76 & 4.89 \\
Z09 & 31.96 & 29.79 & 7.64 & 8.60 & 40.38 & 50.01 & 6.67 & 5.07 \\
Z10 & 33.74 & 29.80 & 7.61 & 8.60 & 44.00 & 49.81 & 7.35 \\
\hline
\end{tabular}

Table 1(b). October 2006 Crystal Ball (Projected) vs. Field Trip (Measured) Data for Relevant Parameters

\begin{tabular}{lllllllll}
\hline Station & \multicolumn{2}{l}{ Water Temp. $\left({ }^{\circ} \mathrm{C}\right)$} & $\mathrm{pH}$ & \multicolumn{3}{c}{ Salinity $(\%)$} \\
\cline { 2 - 8 } & Projected & Measured & Projected & Measured & Projected & Measured & Projected & Measured \\
\hline Z00 & 28.51 & 28.65 & 7.58 & 8.70 & 40.74 & 48.66 & 6.65 & 5.71 \\
Z01 & 27.89 & 27.47 & 8.13 & 8.77 & 41.50 & 50.22 & 6.22 & 5.01 \\
Z05 & 28.14 & 27.44 & 6.19 & 8.75 & 41.59 & 49.36 & 6.89 & 5.35 \\
Z06 & 27.84 & 27.82 & 7.51 & 8.71 & 40.85 & 50.43 & 6.30 & 5.25 \\
Z07 & 28.70 & 28.68 & 7.66 & 8.69 & 40.82 & 47.17 & 6.52 & 5.66 \\
Z08 & 29.15 & 28.79 & 7.61 & 8.69 & 40.79 & 49.56 & 6.89 & 5.80 \\
Z09 & 29.56 & 29.43 & 7.58 & 8.65 & 41.02 & 50.05 & 7.08 & 5.99 \\
Z10 & 28.96 & 29.27 & 7.62 & 8.63 & 46.33 & 49.33 & 7.25 & 6.61 \\
\hline
\end{tabular}

with those generated by Crystal Ball ("Projected" column). The Pearson coefficient was calculated for each parameter, with results shown in Table 2. The closer a Pearson coefficient value is to 1 or -1 , the more positively or negatively correlated the data is, respectively. Based on the uncertainty of the projected results, a value of \pm 0.6 and above is considered acceptable.

Table 2. Pearson Coefficients of Measured vs. Projected Data

\begin{tabular}{ccc}
\hline Parameter & August 2006 & October 2006 \\
\hline Water Temperature & 0.58 & 0.92 \\
pH & -0.97 & -0.18 \\
Salinity & 0.52 & 0.05 \\
DO & 0.53 & 0.86 \\
\hline
\end{tabular}

Preliminary inspection shows the data correlates quite well in both cases, except for the salinity levels in October. The Pearson coefficients reinforce this observation, but they also show that the $\mathrm{pH}$ levels in October also do not correlate well. Both aforementioned values show good to excellent correlation in August, as do all remaining values.

The scope for this study covers ambient water temperature and dissolved oxygen, both parameters whose projected values show good correlation with empirical results.

As the literature points to no major HAB being documented in May within Kuwaiti waters, there was no binary map with which to compare the one generated for May 2006 (Figure 7). As a standalone raster, it can be seen that the southern waters show the highest hotspot propensity. Stations Z07, Z09, Z10 and Z12 show the only green zones in the area, sugges- ting that optimal HAB conditions are only just beginning to develop. This result meshes well with the repeated observations that HABs begin in the south and migrate northwards.

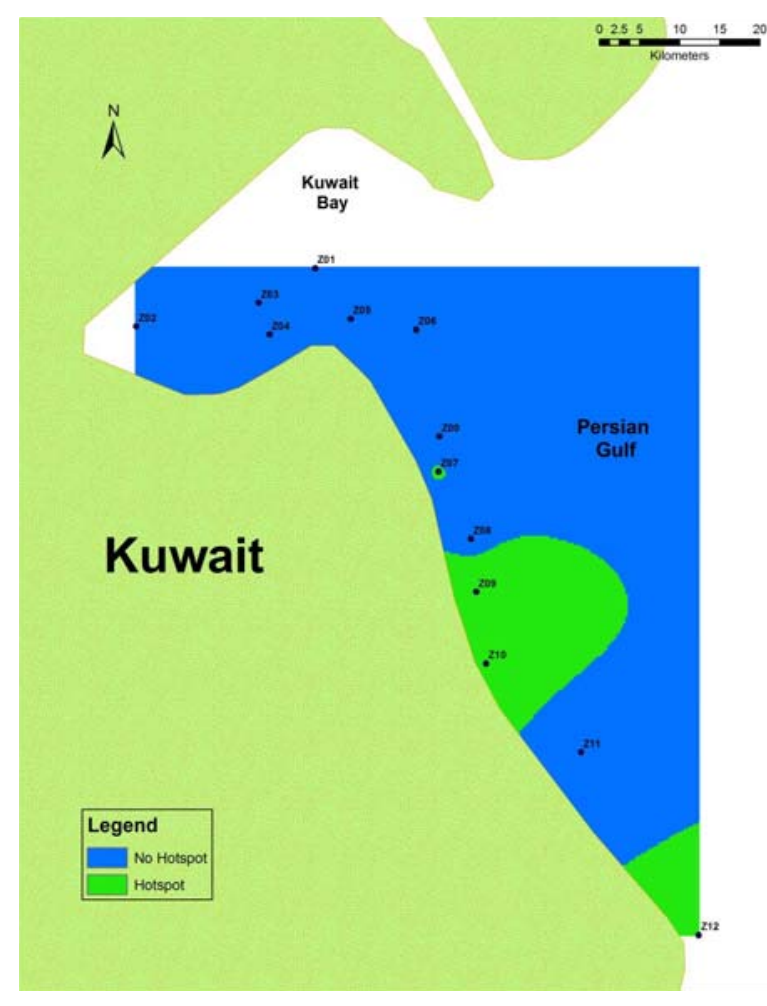

Figure 7. Generated hotspot binary raster on May 2006. 
It is also fitting that these areas represent the preliminary areas of HAB promulgation because of their proximity to the shipping and oil industries in their vicinity. Most telling of this fact is the relatively large zone surrounding stations Z09 and Z10, representing the shipping ports areas of Fahaheel and Mina Abdulla respectively, and station Z10, which is just offshore of a power plant located in Al-Zoor.

The small halo of green surrounding station Z07 may be attributed to heavy recreational use of the waters in that area, which begins to be dominated by boaters, swimmers and jet skiers in the month of May. This is due to the large density of sea clubs, marinas and resorts along that stretch of Kuwaiti coastline.

As the literature points to no major HAB being documented in June within Kuwaiti waters, there was no binary map with which to compare the one generated for June 2006 (Figure 8).

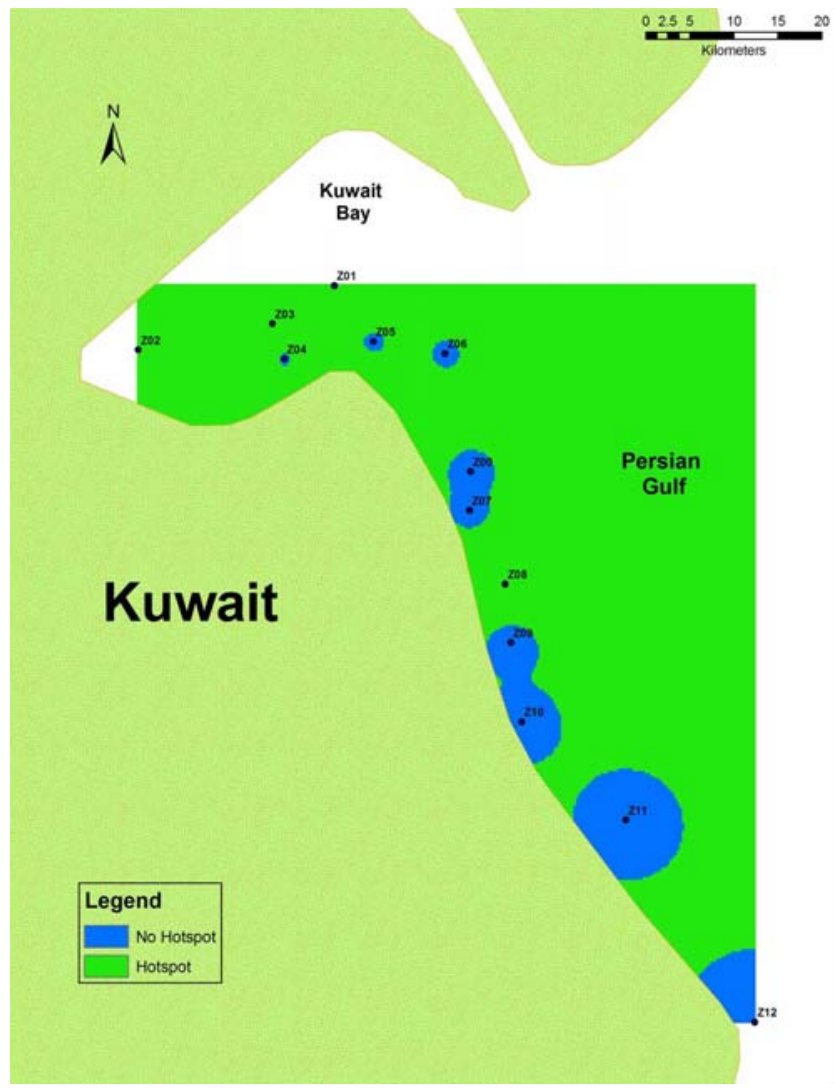

Figure 8. Generated hotspot binary raster on June 2006.

As a standalone raster, it can be seen that virtually the entire area of study is a potential hotspot for HAB promulgation. Of particular interest are the entire middle and western Bay area (stations Z01 through Z04), as well as station Z08 off the mid-southern section of the Kuwait coastline.

This raster suggests that the month of June provides the most optimal conditions for a HAB throughout Kuwaiti waters, and in turn the highest probability of promulgation. This makes sense as the ambient air temperatures are steadily rising to the point where the water is heated to a level that mesophilic species can thrive at without being adversely affected by the compounded heat contributed by industry-based thermal pollution. In addition, more stress is placed on the coastal waters as more people are making recreational use of them due to the school holidays as well as the amicable climate.

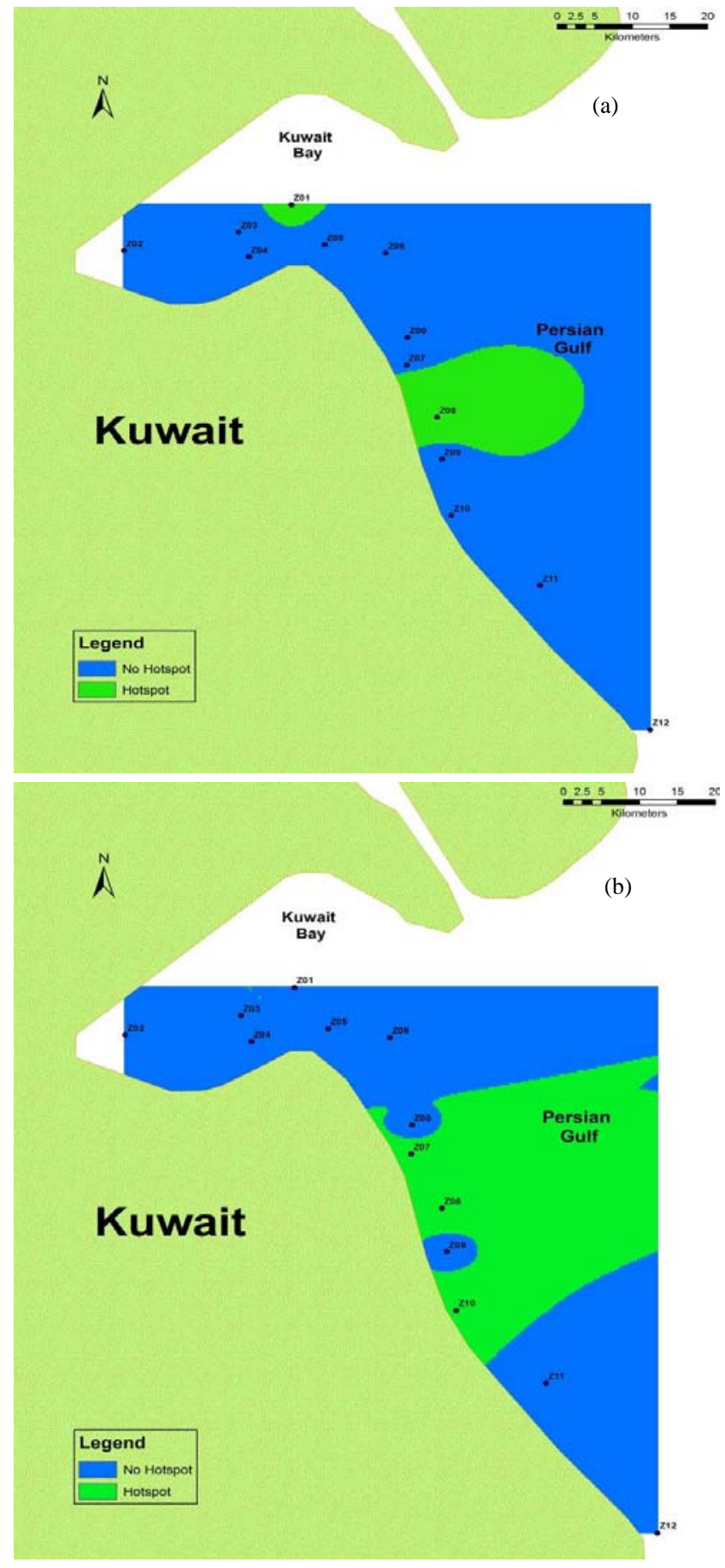

Figure 9. Generated hotspot binary rasters on (a) July 2006 and (b) July 2000. 
The raster generated for July 2006 (Figure 9a) was compared with that generated for July 2000 (Figure 9b). An overall similarity is seen between the two, as they display a hotspot area in the same mid-southern section of Kuwaiti coastal waters. Both rasters show a large area of green surrounding station Z08, with the July 2000 raster also encompassing Z07 and Z10. Some green pixels are also evident near station Z01 and Z03 in the July 2000 raster, which tally with the location of the semi-circular green zone encircling station Z01 in the July 2006 raster.

The month of July is historically the second hottest month of the year in Kuwait. This means a higher demand for air conditioning and therefore greater stress on the power plants and oil refineries. When the thermal effluent of these industries compounds the already present high temperature ambient water, phytoplankton would have a very difficult time surviving for long, if at all, in those conditions. This would be especially true in areas closer to the coast, where the currents have not had ample time to flush the water back into the Gulf and circulate cooler water inwards. This might explain the presence of a blue ring around station Z09 and Z00, as well as the southern waters and Kuwait Bay itself. The above conditions would also hold true for station Z01, as it is in the epicenter of the Bay and therefore more conducive to temperatures preferred by the phytoplankton to thrive.

The raster generated for August 2006 (Figure 10a) was compared with that generated for August 2001 (Figure 10b). Although the latter raster is missing some data, a comparison of sorts can be made with the images at hand. The August 2006 raster shows a concentrated hotspot zone surrounding station Z07 and another surrounding station Z10. The former tallies well with the limited data provided for August 2001, which shows a slightly larger hotspot area stretching from stations Z09 to Z07 and slightly northwards of station Z00. If the pattern of the August 2001 raster were to be extrapolated, the possibility and probability exist that the hotspot zone would have carried on farther to the south, which would correlate with the secondary green halo surrounding station Z10 in the August 2006 raster.

August is historically the hottest month in Kuwait, in addition to being the most vacated. Most families and employees take their holiday time in this month, which reduces the stress on energy requirements and recreational water use. Very high ambient temperatures alone could provide less-than-optimal conditions for HAB promulgation, especially in Kuwait Bay where its characteristic of being a natural harbor reduces flushing time and therefore thermal dissipation. Compounded thermal pollution produced by industry can only worsen the situation. This can explain why the observed HAB of AugustSeptember began towards the end of the month of August and overlapped into September. The August 2006 raster reinforces this theory in its lack of hotspot locations.

The raster generated for September 2006 (Figure 11a) was compared with that generated for September 1999 (Figure 11b) as well as September 2001 (Figure 12b).

When compared with the September 1999 raster, the Sep-

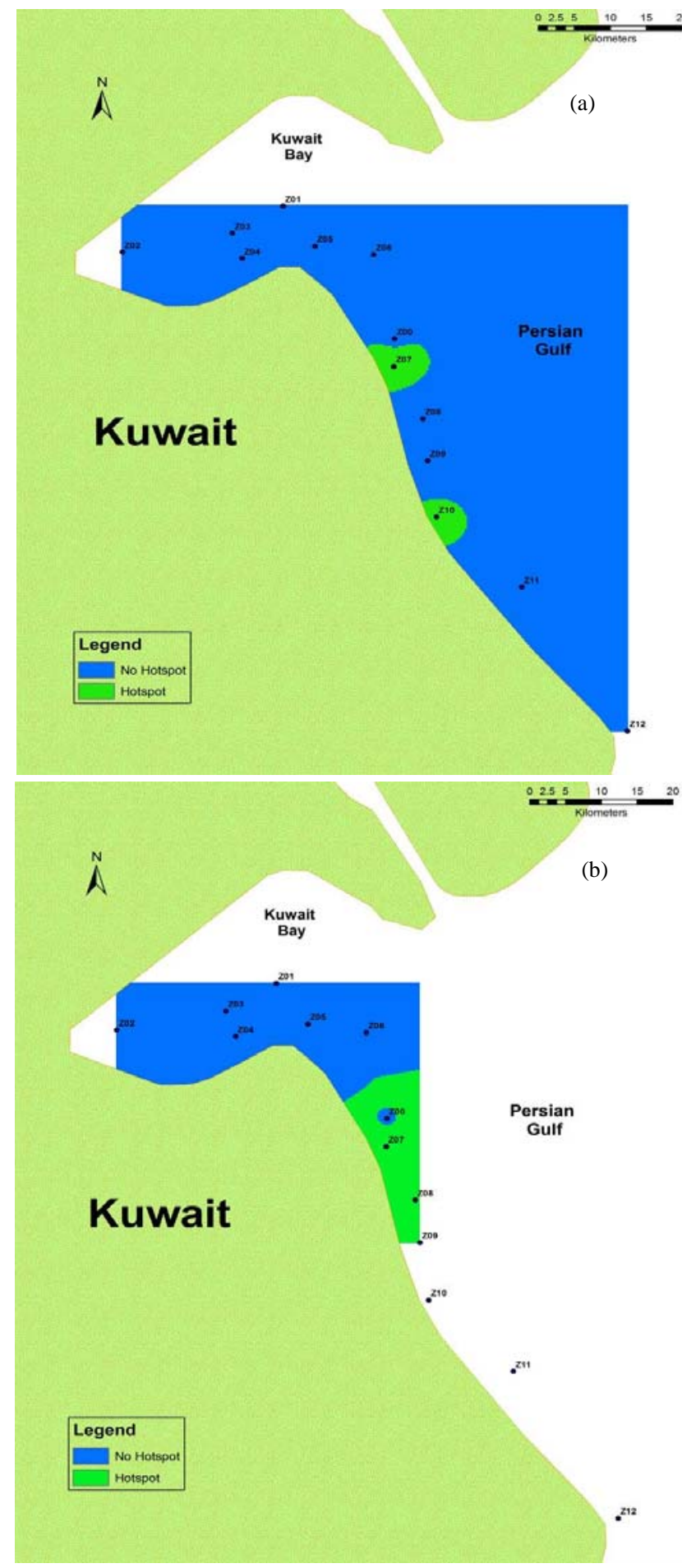

Figure 10. Generated hotspot binary rasters on (a) August 2006 and (b) August 2001.

tember 2006 raster is virtually its inverse: where the former shows large blue "no hotspot" areas along the mid-southern coastline (stations Z00 and Z07 Z10) and Kuwait Bay (stations Z01 Z05), the latter shows a large green hotspot zone extending from station Z04 to the eastern waters of the Gulf, 


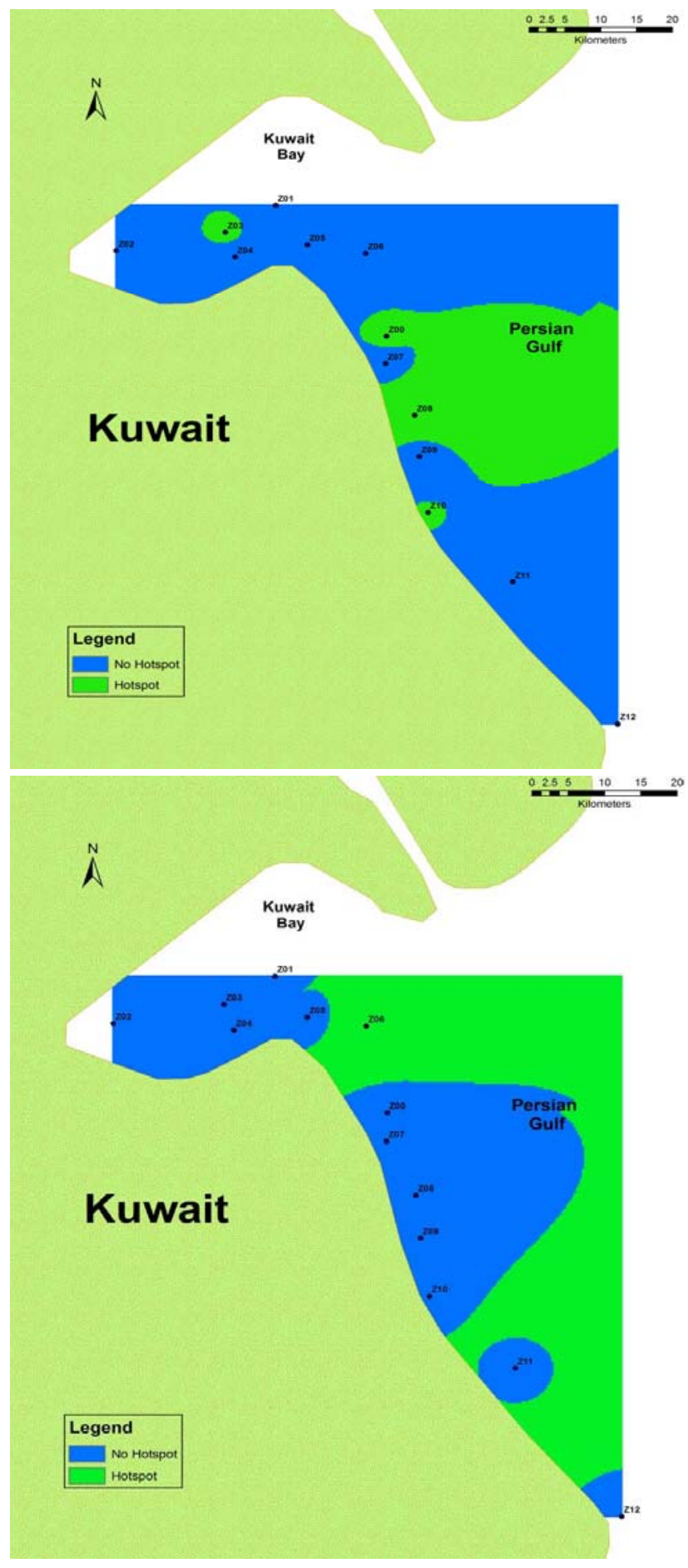

Figure 11. Generated hotspot binary rasters on (a) September 2006 and (b) September 1999.

and as far north as station Z00. In addition, there is a green hotspot zone surrounding station Z03 in Kuwait Bay. September 1999 also shows a large hotspot zone engulfing the southern stations, whereas September 2006 illustrates a large blue no hotpot area in the same region. These rasters represent the first major anomaly in a direct comparison thus far.

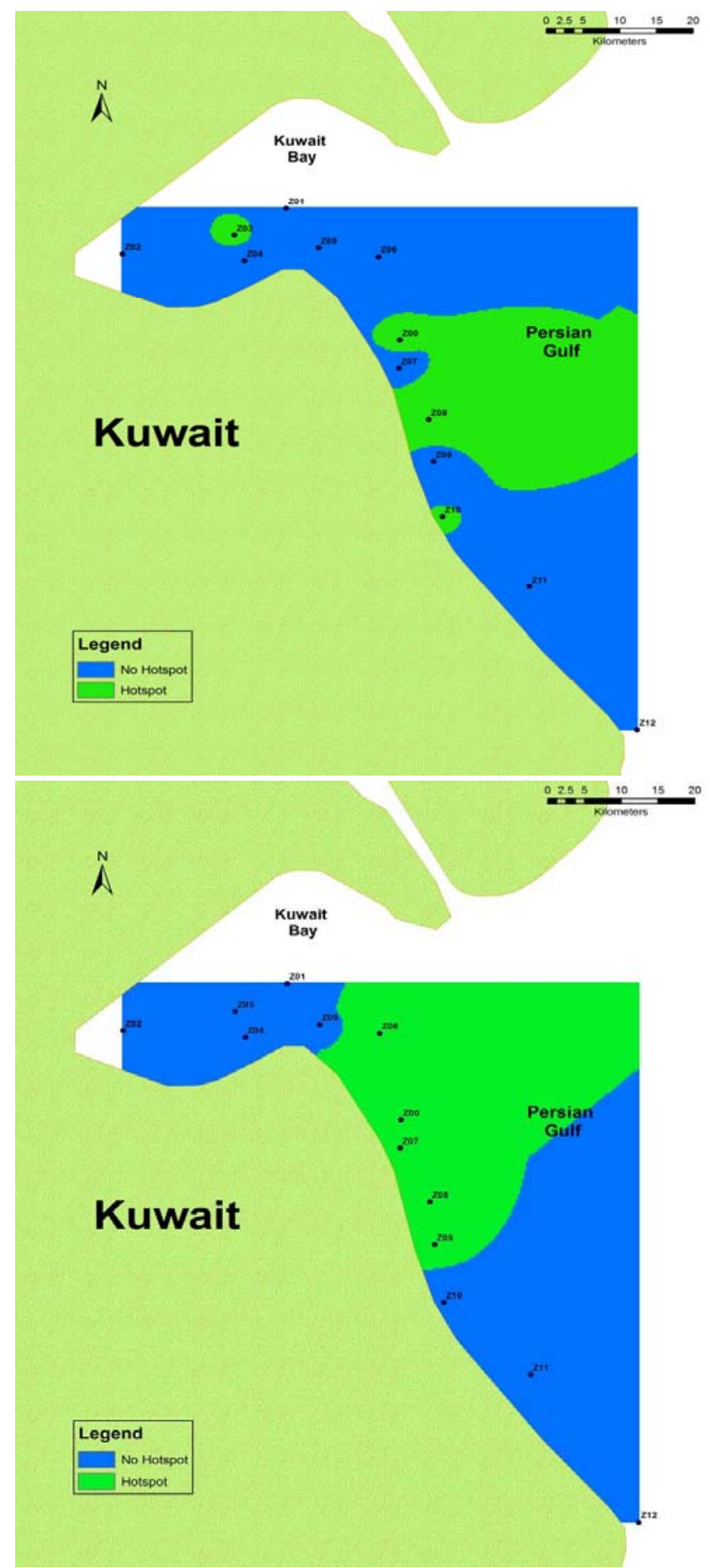

Figure 12. Generated hotspot binary rasters on (a) September 2006 and (b) September 2001.

A comparison between the September 2006 and the September 2001 rasters, however, shows a much more agreeable result. Although the area covered in September 2001 raster is larger (extending from stations Z06 to Z09, including station $\mathrm{Z} 00$ ), the hotspot zones in both rasters appear to fall in roughly the same mid-coastline region and both extend eastwards 


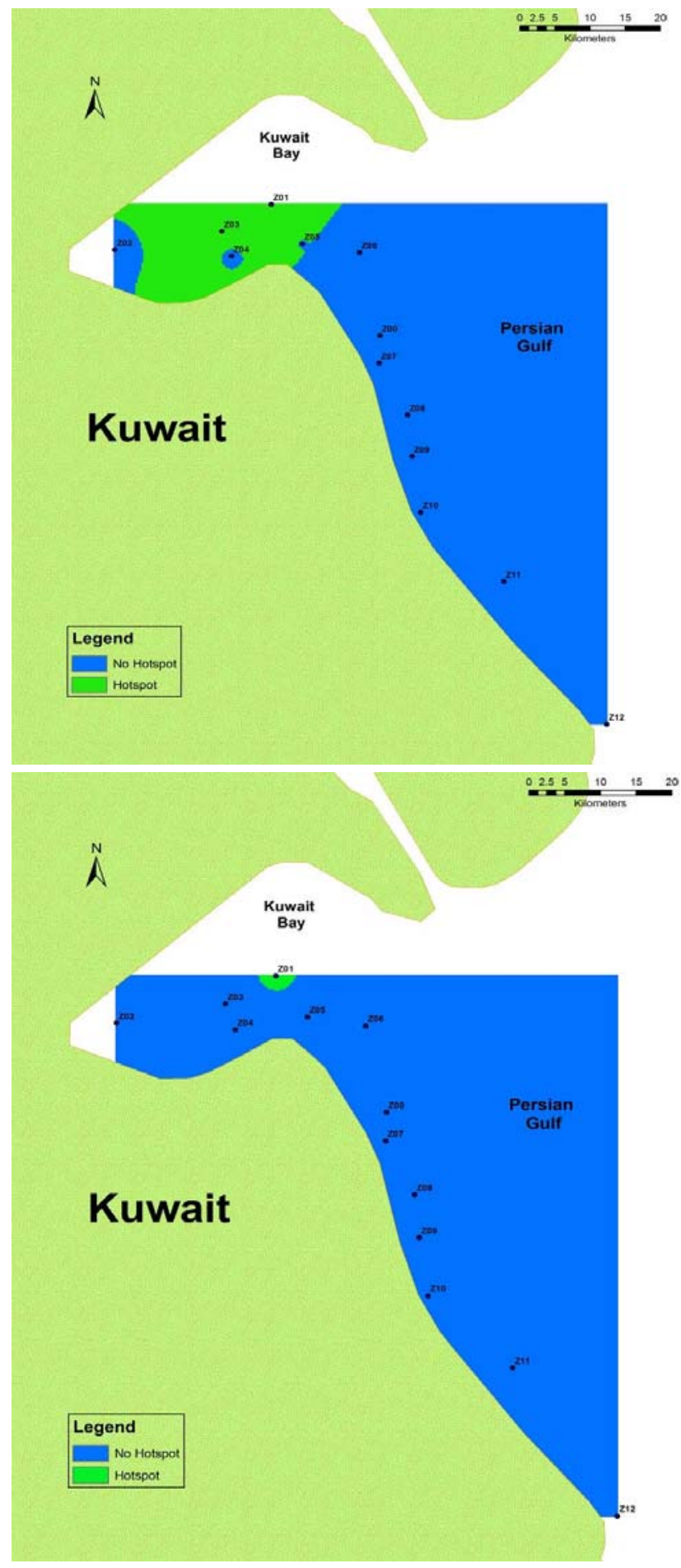

Figure 13. Generated hotspot binary rasters on (a) October 2006 and (b) October 1999.

into the open waters of the Persian Gulf. The main exception in this case is that the September 2006 raster shows a potential HAB hotspot within the Bay itself, which is completely absent in that of September 2001.

At this point in the calendar year, the ambient tempera- ture is still quite high but has dropped enough to comfortably support a phytoplankton bloom in some areas, even with the compounded industrial thermal pollution. In addition, the school year has begun and the vast majority of families and employees have returned from their leaves of absence, thus increasing once again the demand for energy and in turn the environmental stresses associated with it. The heavily industrialized areas of Kuwait, including those around Kuwait Bay, are all contributing their thermal runoff to their respective areas, making them less conducive to HAB promulgation and/or sustenance.

The raster generated for October 2006 (Figure 13a) was compared with that generated for October 1999 (Figure 13b). Both show a hotspot presence exclusive to Kuwait Bay, with the former displaying a much larger green zone (extending from station Z04 to just east of station Z02) than that of the latter (green semicircle around station Z01). There are no hotspots shown anywhere between stations Z06 to Z12 in either raster.

The mean ambient temperature continues to decrease in October, with pleasantly warm temperatures experienced during the day and relatively cooler ones at night. These circumstances make the stagnant and enclosed nature of Kuwait Bay ideal for maintaining the higher temperatures required for HAB promulgation, as opposed to the continuously dynamic nature of the waters to the east and southeast of the Bay.

In addition, documented HAB sightings always describe the transport of a HAB as south-to-north, entering Kuwait Bay for a period of time before advecting outwards towards the Gulf. The rasters generated for October not only reinforce this observation, they suggest that October presents the most optimal conditions for the promulgation of a HAB within Kuwait Bay.

Although the previous rasters representing projected data are generally in tandem with their existing data counterparts, they do not provide a definitive means of establishing that a HAB had indeed existed in the hotspot regions. In other words, there was no solid prediction made. This is further reinforced by the fact that no documented or official HABs were reported for the May-to-October period of 2006. A few eyewitness accounts have been reported of one or two small sightings, but none of the magnitude that would constitute the degree of those that had been observed previously in the national waters of Kuwait.

On a more positive note, the data do show that Kuwait Bay and the national waters to the south of country all display a propensity for the combination of criteria needed to promulgate and/or sustain a $\mathrm{HAB}$, and at their optimal levels. The rasters have demonstrated that the most optimal month for HAB promulgation for the entire study area is June, whilst that for within the Bay itself is in October (with a relatively high probability in September).

Temperature does play a major role in HAB existence, as phytoplankton thrive in mesophilic conditions: this fact is reflected in the pattern of hotspots illustrated by the generated rasters. In theory, May, June, September and October would all provide optimal ambient water temperature conditions for 
the phytoplankton blooms to reach massive proportions, for two reasons:

The ambient air temperature is still at a level where its effects on the surface water temperature are not excessive enough to adversely affect HAB growth.

Energy demands on industry infrastructure are relatively low, which means thermal pollution is limited to certain hours of the day. This allows for a certain amount of mixing taking place between the cooler Gulf waters and those affected by effluent and discharges, thus keeping the ambient water temperature at relatively acceptable mesophilic values.

Another point of interest to be raised is the question of cyclicality. The literature cites three major blooms that occurred in 1999, 2000 and 2001 respectively: no major blooms have been documented since then. A hypothesis could therefore be put forward that HAB promulgation may occur in cycles. Unfortunately, the data in existence to date is insufficient to test it, as it only dates back to 22 years and documentation of major HABs had not started to take place until the 1990's.

It is also important to note that the data provided by KEPA is in a monthly format. This can be detrimental to exhaustively and accurately studying HAB outbreaks because by definition, HABs are ephemeral in nature, not lasting more than a few days at a time. This is why a snapshot of data representing an entire month can be misleading in terms of HAB viability: weather changes from day-to-day and with it the data. In addition, levels of parameters such as nutrient discharges have diurnal as well as long-term patterns, depending on a multitude of factors such as consumer demand, rainfall levels, time of day and so forth. Daily data is therefore a lot more useful when studying short-term phenomena such as HAB promulgation and sustenance.

Another area of interest is the source of the data itself: the monitoring stations. Thirteen stations arranged in their current pattern are adequate for near-shore water quality monitoring, but the potential HAB zone is far greater and not limited to the coastline alone. More stations deployed in the more open national waters between the coast and the major islands would allow for a much higher accuracy of interpolation by IDW, or any other method to be employed. A case in point is the current gap between stations Z11 and Z12, which is large enough to affect interpolation if the country boundaries are taken into account: a test IDW showed an irregular pattern was produced between the two (Figure 14). In addition, the generated area around the island of Failaka to the east of the Bay is inconsistently drawn. It was for those reasons that the current method of placing the country boundary polygon itself as a layer on top of the IDW-generated raster was chosen, as opposed to a more accurate country-borderline boundary.

As it stands, the process used for generating these rasters is a set of modules that need to be neatly packed up into one executable process. A firmer grasp on skills in computer programming would have allowed for that to have taken place, uniting all the processes of data interpolation, extrapolation, file conversion, IDW raster generation and hotspot raster generation into one seamless function. An additional process of animating the binary rasters using a GIF-producing application could also be incorporated into the process, in order to allow for a virtual simulation of hotspot pattern changes over time.

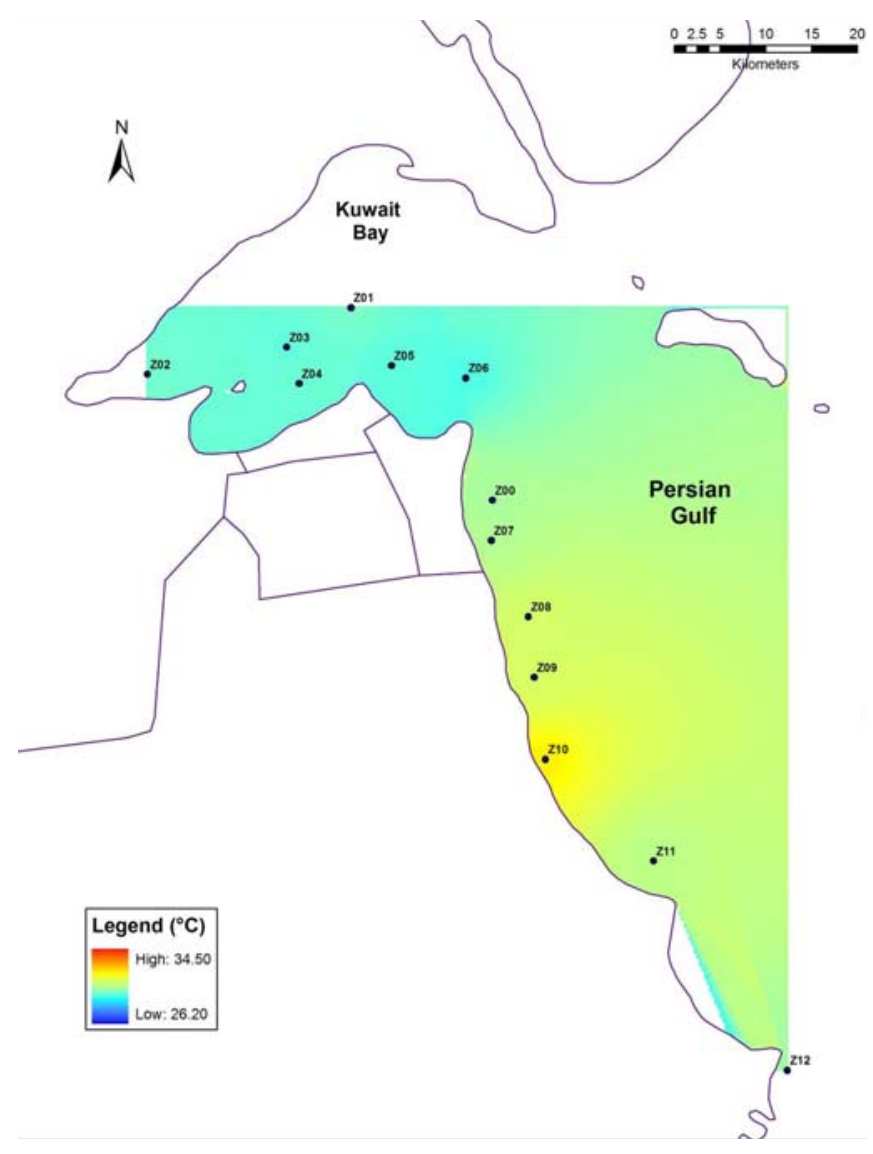

Figure 14. Test IDW of temperature using country border lines as boundaries in September 1999.

\section{Conclusions}

The three past major HABs to have adversely affected the terrestrial waters of Kuwait, and their devastating impacts provided the impetus for this work. The purpose of this study was to establish whether a GIS-based process could be developed that could predict the outbreak of the next major HAB within Kuwaiti national waters, with a focus on Kuwait Bay. The data was obtained from KEPA, an accredited source, and further validated by two field trips conducted in August and September of 2006.

Based on the results, the vast majority of all objectives outlined were met. The review of the literature led to uncovering the most important parameters relevant to HAB promulgation and lifespan. This led to the interpolation and projection of the data as provided by KEPA, allowing the provision of a robust data set for processing and analysis. As the coordinates for each monitoring station were available, a spatial representtation could be developed using GIS for the aforementioned 
data, which then provided the opportunity for application of GIS analysis techniques. This resulted in the generation of HAB hotspot maps, visually outlining the possible areas of HAB promulgation. All of the above modular processes were developed within an efficient technological framework that is userfriendly enough to be applied universally and where needed.

The one aspect of the objectives that was not met was the ability to accurately predict or forecast the next major HAB outbreak with any major degree of certainty. The data frequency was not adequate to provide the information needed to ascertain the onset of an event as ephemeral as a HAB. That having been said, the research conducted throughout this paper forms a firm basis for further study as it has demonstrated the overall propensity for HAB-friendly optimal conditions of the terrestrial waters of Kuwait. History has also shown that, although ephemeral, massive HAB outbreaks could afflict Kuwait at any point in the future where the circumstances may permit it. Also, a possible theory that these outbreaks may be cyclical in nature could also provide further insights into understanding their behavior and complexity.

Collectively, the results show June to be the overall optimal month for HAB promulgation, with October showing the most favorable conditions for outbreaks within Kuwait Bay.

The findings of this research can help engineers, designers and planners alike coordinate the expansion of the infrastructure of Kuwait. The population is growing at a steady rate from year-to-year, and newer cities are constantly being planned in order to keep up with the pace. This means newer power plants, desalination plants, wastewater treatment facilities and other infrastructure that will need to be placed near the only water source that Kuwait possesses: the Persian Gulf. Knowing the location of these hotspots can provide an invaluable tool for plant situation, inflow and outlet locations and any other facet that directly or indirectly affects the quality of Kuwaiti terrestrial waters.

\section{Recommendations for Future Research}

If any study similar to this is to be carried out, daily data should be used. An agreement should be reached with KEPA to allow for such data to be recorded. In a professional project scenario, a liaison who functions as buffer between the project manager and KEPA could be assigned with the task of ensuring those data be procured at the end of each working day. This would make the predictive model that much more accurate based on the relatively short lifespan of any given HAB. The addition of more monitoring stations throughout the area, e.g. in-between stations Z11 and Z12; the area near Failaka Island; several in the area subtending them and so on, would ensure that a more accurate interpolation can take place, thus pinpointing the HAB hotspots with a substantially higher degree of accuracy.

Acknowledgments. The support of both the Kuwait Institute for Scientific Research and Kuwait Environmental Public Authority are greatly appreciated.

\section{References}

Ahn, Y., Shanmugam, P., Ryu, J., and Jeong, J. (2006). Satellite Detection of Harmful Algal Bloom Occurrences in Korean Waters, Harmful Algae, 5, 213-231, doi:10.1016/j.hal. 2005.07.007.

Anderson, D.M. (1994). Red Tides, Sci. Am., 271(2), 52-58.

Anderson, D.M., Glibert, P.M., and Burkholder, J.M. (2002). Harmful algal blooms and eutrophication: nutrient sources, composition and consequences, Eutrophication, 25(4b), 704-726.

Bulgakov, N.G., and Levich, A.P. (1993). The nitrogen: phosphorus ratio as a factor regulating phytoplankton community structure, EReports, Moscow State University-Dept. of Biology. http://www. chronos.msu.ru/EREPORTS/levich_the_nitrogen/levich_the_nitro gen.htm (accessed Jan 10, 2008).

Chen, Q., and Mynett, A.E. (2004). Predicting Phaeocystis globosa Bloom in Dutch Coastal Waters by Decision Trees and Nonlinear Piecewise Regression, Ecol. Mod., 176, 277-290, doi:10.1016/ j.ec olmodel.2003.10.031.

Central Intelligence Agency (2008). The World Factbook (Kuwait), https://www.cia.gov/library/publications/the-world-factbook/geos/ ku.html (accessed Jan 10, 2008).

Fdez-Riverola, F., and Corchado, J.M. (2003). FSfRT: Forecasting System for Red Tides, a Hybrid Autonomous AI Model, App. Artif. Intel., 17, 955-982, doi:10.1080/714858319.

Fdez-Riverola, F., and Corchado, J.M. (2003). CBR Based System for Forecasting Red Tides, Knowledge-Based Systems, 16, 321328, doi:10.1016/S0950-7051(03)00034-0.

Glibert, P.M., Evans, J., and Landsberg, J. (2002). The 2001 Fish Kill in Kuwait Bay: Questions, Causes, Commentary, a Report to the Environment Public Authority, Kuwait.

Glibert, P.M., Landsberg, J.H., Evans, J.J., Al-Sarawi, M.A., Faraj, M., Al-Jarallah, M.A., Haywood, A., Ibrahem, S., Klesius, P., Powell, C., and Shoemaker, C. (2002). A fish kill of massive proportion in Kuwait Bay, Arabian Gulf, 2001: the roles of bacterial disease, harmful algae, and eutrophication, Harmful Algae, 1, 215231, doi:10.1016/S1568-9883(02)00013-6.

Heil, C.A., Glibert, P.M., Al-Sarawi, M.A., Faraj, M., Behbehani, M., and Husain, M. (2001). First record of a fish-killing Gymnodinium sp. bloom in Kuwait Bay, Arabian Sea: chronology and potential causes, Mar. Ecol. Prog. Ser., 214, 15-23.

Inside Line. Seeking Thermal Refuges (2008). http://www. insideline. net/2005/bucca-thermal-refuge.htm (accessed Jan 10, 2008).

Lam, I.H.Y., and Hodgkiss, I.J. (2002). Telemetry for Early Warning of Red Tides, Sea Tech., 62-64.

Lee, J.H.W., Hodgkiss, I.J., Wong, K.T.M., and Lam, I.H.Y. (2005). Real Time Observations of Coastal Algal Blooms by an Early Warning System, Estuar. Coast. Shelf Sci., 65, 172-190, doi:10.1016/j. ecss.2005.06.005.

Muttil, N., and Lee, J.H.W. (2005). Genetic Programming for Analysis and Real-time Prediction of Coastal Algal Blooms, Ecol. Mod., 189, 363-376, doi:10.1016/j.ecolmodel.2005. 03.018.

Redfield, A.C. (1934). On the Proportions of Organic Derivations in Seawater and Their Relation to the Composition of Plankton, James Johnson Memorial Volume, University Press of Liverpool, 177-192.

Reisenett: Maps of the Middle East, http://www.reisenett.no /map_co llection/middle_east.html

Rodriguez-Benito, C., and Haag, C. (2004). Applications of ENVISAT Data in the South of Chile: Monitoring Algal Blooms and Other Coastal Ocean Features Using MERIS and AATSR Imagery, Gayana (Concepc.), 68(2), 508-513.

Roelke, D., and Buyukates, Y. (2001). The diversity of harmful algal blooms-triggering mechanisms and the complexity of bloom initi- 
ation, Hum. Ecol. Risk Assess, 7(5), 1347-1362.

Sacau-Cuadrado, M., Conde-Pardo, P., and Otero-Tranchero, P. (2003). Forecast of Red Tides off the Galician Coast, Acta Astronaut., 53, 439-443, doi:10.1016/S0094-5765(03)00135-8.

Shepard, D. (1968). A two-dimensional interpolation function for iregularly-spaced data, Proceedings of the 1968 ACM National Conference, $517-524$

Stumpf, R.P. (2001). Applications of Satellite Ocean Color Sensors for Monitoring and Predicting Harmful Algal Blooms, Hum. Ecol. Risk Assess, 7(5), 1363-1368.

Subba Rao, D.V., Al-Hassan, J.M., Al-Yamani, F., Nageswara Rao, C.V., and Al-Hassan, M. (2003). Elusive red tides in Kuwait coastal waters, the Intergovernmental Oceanographic Commission of UNESCO: Harmful Algae News, 24, 13-16.

United States Environmental Protection Agency (2008). Aquatic Life Criteria, http://www.epa.gov/waterscience/criteria/dissolved/dofact s.html (accessed Jan 10, 2008).

United States Environmental Protection Agency (2008). Terms of Environment: Glossary, Abbreviations and acronyms, http://www.epa. gov/OCEPAterms/gterms.html (accessed Jan 10, 2008).

Wynne, T.T., Stumpf, R.P., Tomlinson, M.C., Ransibrahmanakul, V., and Villareal, T.A. (2005). Detecting Karenia brevis Blooms and Algal Resuspension in the Western Gulf of Mexico with Satellite Ocean Color Imagery, Harmful Algae, 4, 992-1003, doi:10.1016/j. hal.2005.02.004.

Yanagi, T., Inoue, K., Montani, S., and Yamada, M. (1997). Ecological Modeling as a Tool for Coastal Zone Management in Dokai Bay, Japan, J. Mar. Sys., 13, 123-136, doi:10.1016 /S0924-7963(97) 00006-7.

Anastassopoulos, A., Nguyen, S. and Xu X. (2004). On the use of HYSPLIT model to study air quality in Windsor, Ontario, Canada, Environmental Informatics Archives, 2, 375-383.

Collett, R.S. and Dyuyemi, K. (1997). Air quality modeling: a technical review of mathematical approaches, Meteorol. Appl., 4(3), 235-246, doi:10.1017/S1350482797000455.

Draxler, R.R. and Hess, G.D. (1997). Description of the Hysplit_4 modeling system, NOAA Tech. Mem. ERL ARL-224, pp. 24.

Draxler, R.R. and Hess, G.D. (1998). An Overview of the Hysplit_4 Modeling System for Trajectories, Dispersion, and Deposition, Aust. Met. Mag., 47, 295-308.
Draxler, R.R. (2003). Evaluation of an ensemble dispersion calculation, J. Appl. Meteorol., 42, 308-317, doi:10.1175/1520-0450 (200 3) $042<0308$ :EOAEDC $>2.0$. CO;2.

Draxler, R.R. and Rolph G.D. (2003). HYSPLIT (HYbrid Single-Parti cle Lagrangian Integrated Trajectory) Model access via NOAA ARL READY Website http://www.arl.noaa.gov/ready/hysplit4.htm

Hsu, Y., Holsen, T.M. and Hopke, P.K. (2003). Locating and Quantifying PCB Sources in Chicago: Receptor Modeling and Field Sampling, Environ. Sci. and Technol., 37(4), 681-690, doi:10.1021 les025531x S0013-936X(02)05531-1.

Johnson, R.A. (2005). Miller and Freund's Probability and Statistics for Engineers, 7th edition, Pearson Education, Inc. London.

Luginaah, I., Xu, X., Fung, K., Grgicak-Mannion, A., Wintermute, J., Wheeler, A.J., Brook, J. (2006). Establishing the Spatial Variability of Ambient Nitrogen Dioxide in Windsor, Ontario, Int. J. Environ. Stud., 63(4), 487-500, doi:10.1080/00207230600802122.

NOAA. (1999). NOAA Technical Memorandum ERL ARL-230, pp. 35.

Perkauskas, D. (2000). Evaluation of possible air pollution transport from the Ignalina nuclear power station in regional scale, Proceedings of Millenium (24th) NATO/CCMS International Technical Meeting on Air Pollution Modeling and it's Application, Boulder, Colorado, pp. 212-213.

Poissant, L. (1999). Potential sources of atmospheric total gaseous mercury in the St. Lawrence River valley, Atmos. Environ., 33(16), 2537-2547, doi:10.1016/S1352-2310(98)00207-6.

Rolph, G.D. (2003). Real-time Environmental Applications and Display System (READY) Website. http://www.arl.noaa.gov/ready/hy split4.html.

Texas Natural Resource Conservation Commission (2004). Trajectories for Texas Locations. http://www.tnrcc.state.tx.us/updated/mo nops/data/trajectories/maintraj.html.

Wheeler, A.J., Xu, X., Smith-Doiron, M., Gilbert, N. and Brook, J. (2006). Intra-urban variability of air pollution: monitoring and modelling of PM2.5, PM2.5-10, and NO2, Epidemiology, 17(6), S243.

Zannetti, P. and Puckett, K. (2004). Air Quality Modeling: Theories, Methodologies, Computational Techniques, and Available DataBases and Software-Volume I-Fundamentals, A\&WMA and the EnviroComp Institute, pp. 430. 